\title{
Pelatihan Pemanfaatan Program Mendeley Dekstop dalam Pembuatan Citasi Karya Ilmiah bagi Mahasiswa di Kabupaten Ponorogo
}

\author{
Prihma Sinta Utami ${ }^{1}$, Ambiro Puji Asmaroini ${ }^{2}$, Hadi Cahyono ${ }^{3}$ \\ 123Jurusan Pendidikan Pancasila dan Kewarganegaraan, Universitas Muhammadiyah \\ Ponorogo \\ Email: prihmasinta@gmail.com \\ Email: ambirop@gmail.com \\ Email: hadicahyono0@gmail.com
}

Submitted: $09-10-2020$

Revised: 24-11-2020

Accepted: $27-12-2020$

\begin{abstract}
The development of information technology in the digital era is currently increasing and also influencing the world of education. This also affects students' ability to be able to take advantage of applications relating to the development of digital literacy skills, especially in writing scientific papers. In the world of academia, currently scientific work is one of the demands and even obligations, so it also demands students to follow its developments. The increasing prevalence of plagiarism cases in academia is also a scourge for students, especially for students in the final level of Ponorogo Regency, here the sample is students of Muhammadiyah University of Ponorogo. Therefore, it is necessary to prepare from the beginning how literacy procedures properly and correctly through the help of a program application so that later students are able to make good manager references. The method applied in this community service with partners, namely students of Muhammadiyah University of Ponorogo, especially in semesters 6 and 8, will be introduced to the Mendeley desktop program application in making citation of scientific papers. This community service activity has been successfully carried out for two online meetings. The first online meeting activity provided an explanation of the function of the mendeley desktop program, the function of tools in the mendeley desktop program and assisting students in the use of the mendeley desktop in making scientific papers. At the second meeting, continued assistance was carried out on the use of the Mendeley application and confirmation in making scientific papers with the help of the Mendeley desktop application.
\end{abstract}

Keywords: Mendeley Desktop, Scientific Papers, Reference Manager, Training.

\begin{abstract}
Abstrak
Perkembangan teknologi informasi dalam era digital saat ini semakin meningkat dan juga mempengaruhi dalam dunia pendidikan. Hal ini berpengaruh juga dalam kemampuan mahasiswa untuk bisa memanfaatkan aplikasi-aplikasi yang berkenaan dengan pengembangan kemampuan literasi digital, khususnya dalam penulisan karya ilmiah. Dalam dunia akademisi saat ini karya ilmiah menjadi salah satu tuntutan bahkan kewajiban, sehingga menuntut pula bagi mahasiswa untuk mengikuti perkembangannya. Semakin maraknya tentang kasus-kasus plagiasi dalam dunia akademisi juga menjadi momok bagi mahasiswa khususnya bagi mahasiswa di Kabupaten Ponorogo tingkat akhir, disini sample adalah mahasiswa Universitas Muhammadiyah Ponorogo. Oleh karena itu, perlu disiapkan sejak awal bagaimana tata cara literasi dengan baik dan benar melalui bantuan suatu aplikasi program agar nantinya mahasiswa mampu membuat referensi manager dengan baik. Metode yang diterapkan dalam pengabdian masyarakat ini dengan mitra yaitu mahasiswa Universitas Muhammadiyah Ponorogo khususnya semester 6 dan 8 akan dikenalkan tentang aplikasi program mendeley desktop dalam pembuatan citasi karya ilmiah. Kegiatan pengabdian ini telah berhasil dilakukan selama dua kali pertemuan secara daring (online). Kegiatan pertemuan daring pertama dengan memberikan penjelasan materi fungsi program mendeley desktop, fungsi tools dalam program mendeley desktop serta pendampingan mahasiswa dalam penggunaan mendeley desktop dalam
\end{abstract}


pembuatan karya ilmiah. Pada pertemuan kedua dilaksanakan pendampingan lanjutan penggunaan aplikasi mendeley serta konfirmasi dalam pembuatan karya ilmiah dengan bantuan aplikasi mendeley desktop.

Kata Kunci: mendeley dekstop, karya ilmiah, referensi manager, pelatihan.

\section{PENDAHULUAN}

Perkembangan era revolusi industri $\quad 4.0 \quad$ semakin mengedepankan semua lini kehidupan dengan menggunakan kemampuan teknologi dan informasi. Kemampuan penggunaan teknologi ini juga berkaitan dengan kemampuan literasi seseorang untuk semakin maju lagi. Kemampuan literasi pada umumnya dibagi menjadi 3 hal, literasi media, literasi digital dan literasi manusia. Tiga hal literasi ini saat ini dituntut untuk dikembangkan dan dapat berjalan dengan seimbang. Hasil dari pemanfaatan tiga literasi ini nampak pada semakin banyaknya publikasi ilmiah elektronik (eresources) yang sudah tersedia secara daring sehingga penyebaran informasi ilmiah dapat tersebar cepat ke seluruh penjuru dunia (Ginanjar, 2018). Mahasiswa merupakan orang yang belajar di perguruan tinggi (KBBI, 2008). Mahasiswa sebagai manusia yang belajar di perguruan tinggi merupakan salah satu kelompok akademisi saat ini dituntut mampu menyampaikan suara, pendapat, aspirasi, maupun menyampaikan kajian hasil penelitian melalui tulisan karya ilmiah yang berbobot dan dapat dipertanggungjawabkan kebenarannya. Sebagai skill mahasiswa dalam penusunan karya ilmiah yang berkualitas.

Berkenaan dengan keterlibatan mahasiswa dalam sumbangsih dunia akademis khususnya dalam hal literasi ini, saat ini semakin banyak dijumpai kasus-kasus terkait literasi yaitu tingginya angka plagiasi pada karya ilmiah mahasiswa, seperti yang disampaikan oleh septiyani (2015) dalam kompasiana edisi 24 Juni 2015 bahwa kegiatan plagiarisme sudah mendarah daging di negara Indonesia, khususnya bagi mahasiswa S1. Hal ini tidak jauh berbeda dengan kondisi yang dialami pada mitra pengabdian yaitu mahasiswa tingkat akhir di Kabupaten Ponorogo dimana masih banyak dijumpai tingginya angka plagiasi pada beberapa tugas karya ilmiah, bahkan pembuatan tugas akhir. Dengan perkembangan teknologi yang semakin maju, layanan-layanan di google.com yang menyediakan berbagai macam informasi dengan mudah copy paste. Selain itu, penulisan karya ilmiah 
dalam perkuliahan masih banyak dijumpai tata cara penulisan, rujukan atau cara citasi mahasiswa yang masih salah dan tidak ada kesesuaian antara rujukan isi dan referensi. Sebagian besar dalam karya ilmiah mahasiswa banyak dijumpai kasus copy paste pada isi artikel maupun dalam daftar pustaka. Selain itu mitra yaitu mahasiswa juga sering mengalami kesulitan terkait lupa dalam pengambilan artikel rujukan untuk hasil karya ilmiahnya. Sebagian besar mahasiswa saat ini sudah diwajibkan untuk mencari data, rujukan atau berita melalui jurnal baik secara online maupun offline. Namun apabila artikel ilmiah yang sudah didownload tidak didokumentasikan dengan baik maka akan menyulitkan ditemukan kembali apabila sewaktu-waktu diperlukan (Windarto, Hartama, \& Wanto, 2018). Dapat dipastikan bahwa mitra masih sangat terkendala dalam kemampuan membuat referensi manager artikel ilmiah dengan baik, praktis, dan benar.

Berangkat dari permasalahan di atas menjadi salah satu perhatian kepada para dosen untuk lebih banyak mengenalkan mahasiswa dengan dunia literasi yang sehat, baik dan benar. Budaya literasi ini, saat ini tidak hanya cukup dikenalkan secara manual atau otodidak melalui pembelajaran langsung namun sudah dipermudah dengan bantuan program-program komputer untuk mengurangi angka plagiasi. Salah satu program yang wajib ditawarkan pada mahasiswa adalah bantuan program mendeley desktop.

Program mendeley desktop ini sangat berperan dalam memerangi plagiarisme karena software ini membantu mengelola berbagai referensi serta membuat bibliografi secara otomatis dengan format yang berbeda (Fitriana et al., 2014). Perlu diketahui plagiarisme merupakan tindakan penjiplakan dan melanggar hak cipta. Bentuk-bentuk plagiarisme meliputi: mencantumkan informasi/data/ide tanpa menyebutkan sumbernya, mencantumkan kara per kata, bahkan mengutip tulisan sendiri tanpa menyebutkan sumbernya (Wahyuni, 2018). Adapun alasan dilakukannya plagiarisme antara lain: 1) Kemudahan informasi yang tersedia dengan adanya internet, 2) Tekanan publikasi dari tuntutan akademik baik dosen maupu mahasiswa yang mengejar target akademik, 3) Kurang percaya diri dan kurang terampil dalam menulis terlebih pada penulis pemula, 4) Menulis artikel terburu-buru dan di bawah tekanan, 5) Kurangnya pemahaman dan kesadaran mengenai plagiarisme, 
Kurangnya kesadaran bahwa walaupun orang lain memberikan teks orisinal tetap tidak diperkenankan melakukan penyalinan tanpa menyebutkan sumber orisinal, 7) Beberapa penulis meyakini bahwa tidak masalah menulis ulang konsep/data yang sudah mereka miliki (self plagiarisme) publikasi sebelumnya tanpa menuliskan sumber (self citation) dengan pedoman tidak menyalin karya orang lain, dan 8) Telah terbiasa melakukan plagiarisme dipermudah dengan adanya internet dan komputer, serta melakukan plagiarisme di masa lalu belum pernah tertangkap hingga saat ini (Debnath dalam Shadiqi, 2019).

Hasil penelitian Arista (2015) menyatakan bahwa mahasiswa pernah melakukan plagiat dengan berbagai alasan, antara lain karena budaya dosen dalam mengajar, orientasi nilai dan IPK, akses informasi yang mudah, faktor ekonomi, minimnya pengawasan, dan minimnya pengetahuan tentang plagiat. Dari hasil penelitian tersebut, peran dosen sangat besar dalam mendidik mahasiswa agar tidak melakukan plagiarisme, dengan memberikan pengawasan dan menanamkan pengetahuan tentang perbuatan buruk plagiarisme.
Program mendeley desktop ini nantinya akan membantu mitra yaitu mahasiswa dalam melakukan citasi atau rujukan karya ilmiah secara praktis, baik dan benar. Program mendeley desktop inipun juga dapat dioperasikan secara offline pada komputer dengan syarat artikel-artikel yang akan digunakan sudah didokumentasikan didalam program tersebut. Hal ini tentunya akan sangat membantu mitra dalam menyelesaikan tugas dosen serta tugas akhir serta mengurangi bentuk plagiarisme.

Berdasarkan

hasil pengamatan, dikemukakan permasalahan mahasiswa tingkat akhir di Kabupaten Ponorogo khususnya di Universitas Muhammadiyah Ponorogo prodi PPKn sebagai berikut:

a. Kurangnya kemampuan literasi digital pada mahasiswa tingkat akhir

b. Kuranganya kemampuan pembuatan referensi manager artikel dengan baik dan benar

c. Kurangnya pemahaman tentang pemanfaatan program mendeley desktop dalam pembuatan karya ilmiah mahasiswa tingkat akhir

d. Perlunya pendampingan bagi mahasiswa tingkat akhir

e. Ponorogo dalam pemanfaatan program mendeley desktop dalam citasi karya ilmiah. 
Solusi yang diberikan dalam

kegiatan ini adalah:

a. Memberikan pemahaman materi tentang fungsi program mendeley desktop untuk pembuatan citasi karya ilmiah kepada mahasiswa di Kabupaten Ponorogo

b. Mendampingi mahasiswa di Kabupaten Ponorogo dalam penginstalan program mendeley desktop serta penggunaannya dalam citasi karya ilmiah, pembuatan bibiografi, hingga pembuatan referensi manager dengan baik dan benar.

\section{METODE PELAKSANAAN}

Berdasarkan permasalahan yang dihadapi oleh mitra tersebut dapat ditanggulangi atau diselesaikan melalui beberapa hal berikut, yaitu:

a. Menetapkan target peserta kegiatan yaitu mahasiswa prodi PPKn Universitas

Muhammadiyah Ponorogo semester 6 dan 8 .

b. Melakukan sosialisasi pelaksanaan kegiatan pelatihan kepada mahasiswa melalui penyebaran undangan

c. Melaksanakan kegiatan dengan penyajian materi, pendampingan pemanfaatan program mendeley desktop, diskusi serta tanya jawab.

\section{HASIL DAN PEMBAHASAN}

Kegiatan pengabdian kepada masyarakat ini dilakukan 2 tahap dengan materi pembahasan yang berbeda dengan menggunakan system daring (online) melalui platform zoom. Pada tahap pertama atau pertemuan pertama dimulai dengan memberikan materi tentang fungsi program mendeley desktop, fungsi tools dalam program mendeley desktop, serta pendampingan penggunaan aplikasi software program mendeley desktop.

Pelaksanaan pemberian materi pada tahap pertama ini dilakukan pada Hari Selasa, tanggal 02 Juni tahun 2020 pada pukul 09.00-12.00 WIB. Pada pertemuan pertama ini diikuti oleh 66 peserta yang terdiri dari gabungan mahasiswa PPKn Universitas Muhammadiyah Ponorogo semester 5, 7 dan 9 serta mahasiswa STKIP PGRI Ponorogo semester akhir serta beberapa bapak ibu dosen pembimbing tugas akhir. Pada pertemua pertama materi disampaikan oleh Ibu Prihma Sinta Utami, M.Pd beserta bapak Hadi Cahyono, M.Pd, berikut gambar 1 pelaksanaan kegiatan penyampaian materi secara daring (online) melalui aplikasi via zoom. 


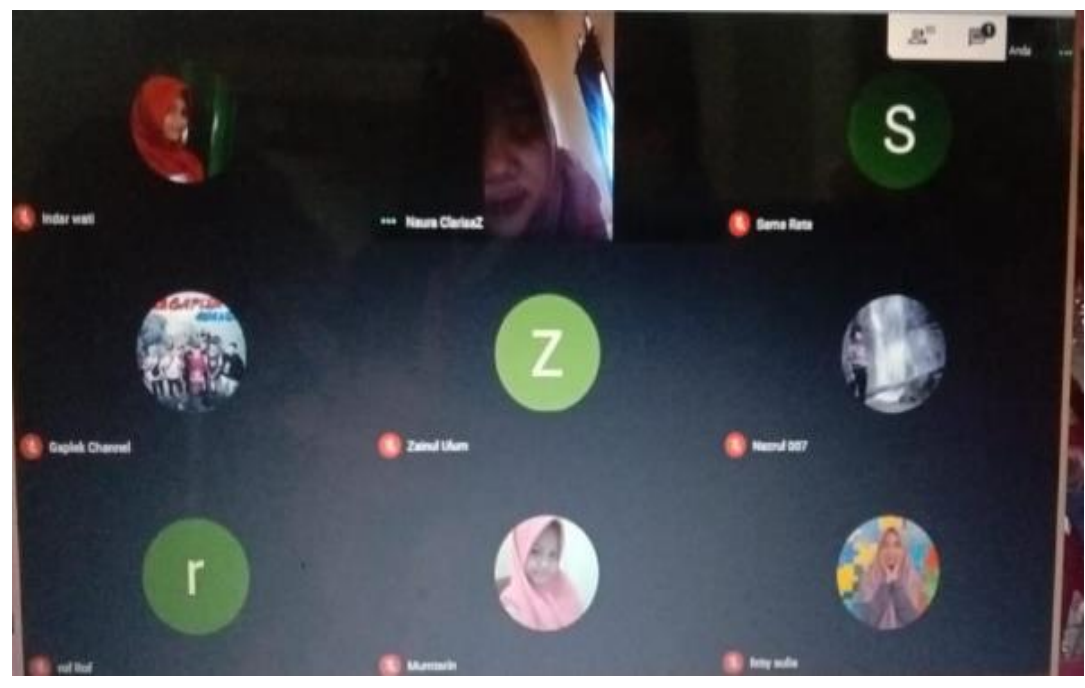

Gambar 1. Peyampaian materi pertemuan pertama tentang aplikasi Mendeley

Pada pertemuan pertama ini difokuskan pada pengantar materi pentingnya aplikasi mendeley desktop dalam penulisan artikel karya ilmiah khususnya bagi tugas akhir mahasiswa. Mahasiswa begitu antusias dalam mengikuti kegiatan, terlebih pada masa pandemic covid ini kebijakan baru kampus Universitas Muhammadiyah Ponorogo tugas akhir atau skripsi dapat digantikan dengan artikel ilmiah yang sudah dipublikasikan. Melalui kegiatan ini mahasiswa banyak bertanya terkait aplikasi secara nyata dalam penggunaan aplikasi mendeley baik untuk citasi di bagian isi ataupun dalam penggunaan daftar pustaka. Dari hasil pertemuan pertama rata-rata mahasiswa ataupun sebagian dosen pembimbing tugas akhir masih merasa bingung dalam rujukan secara sistematis penggunaan aplikasi pada artikel yang sudah ada. Pada pertemuan pertama ini seluruh peserta diwajibkan sudah mendownload aplikasi mendeley desktop sehingga pada pertemuan pertama ini peserta dapat langsung praktek aplikasi secara langsung. Pada akhir pertemuan pertama ini diberikan kesempatan kepada perwakilan peserta untuk melakukan uji coba penggunaan aplikasi secara langsung. Selanjutnya dalam melihat implementasi penggunaan aplikasi mendeley desktop ini dalam artikel atau rancangan artikel mahasiswa akan dilanjutkan pada pertemuan kedua.

Pertemuan kedua kegiatan pelatihan pendampingan ini dilaksanakan pada hari Selasa, 09 Juni 2020. Masih sama dengan 
pertemuan pertama kegiatan dilakukan secara daring (online) menggunakan platform zoom. Kegiatan dilaksanakan pada pukul 09.00-12.00. Peserta pada pertemuan kedua ini masih sama yaitu gabungan mahasiswa PPKn Universitas Muhammadiyah Ponorogo semester 5, 7 dan 9 serta semester akhir serta beberapa bapak ibu dosen pembimbing tugas akhir.

Pada pertemuan kedua ini ditargetkan seluruh peserta sudah menghasilkan mini karya ilmiah dengan menggunakan aplikasi mendeley desktop dalam penggunaan citasi di bagian isi ataupun dalam penggunaan daftar pustaka. Setiap peserta wajib mengirimkan hasil mini artikel yang telah menggunakan mendeley desktop beserta perwakilan beberapa peserta untuk melakukan presentasi saat kegiatan berlangsung. Dari hasil yang didapat, kurang lebih sebesar 80\% dari peserta telah menyusun mini artikelnya dengan menggunakan aplikasi mendeley desktop dengan baik dan terstruktur. Adapun jumlah seluruh mahasiswa peserta pelatihan 13 mahasiswa semester 5, 18 mahasiswa semester 7 , dan 2 mahasiswa semester 9 . Total peserta pelatihan 33 mahasiswa. Sehingga $80 \%$ ketercapaian mahasiswa yang mampu menyusun artikelnya menggunakan program mendeley desktop berjumlah 26 mahasiswa. Ketercapaian ini selaras dengan hasil pelatihan yang dilaksanakan oleh Windarto, Hartama, Wanto, dan Parlina (2018) yang menyatakan bahwa ada pada saat pelaksanaan sesi pre-test, peserta test maksimal dapat menjawab 9 soal dengan benar sebanyak 12,5\% sementara pada sesi post test, peserta mampu menjawab semua soal dengan benar sebanyak 10 soal sebesar 25\%. Dari hasil tersebut dapat disimpulkan bahwa mahasiswa STIKOM Tunas Bangsa Pematangsiantar (S1) dan mahasiswa AMIK Tunas Bangsa Pematangsinar (D3) sebelum dilaksanakannya pelatihan, meeka kurang dalam membuat referensi karya ilmiah. Setelah pelaksanaan pelatihan, nampak peningkatan pengetahuan mahasiswa secara signifikan. Rata-rata mereka memperoleh cukup banyak tambahan pengetahuan dan mampu mengerjakan soal dan referensi membuat citasi karya ilmiah semakin baik. Dengan kegiatan pelatihan mendeley desktop ini dapat dimanfaatkan dan dioptimalkan dalam penggunaan program ini sebagai sarana pendukung pembuatan referensi karya ilmiah yang baik dan benar.

Melihat dari hasil presentasi mahasiswa Universitas Muhammadiyah Ponorogo, ratarata peserta telah menguasai 
penggunaan aplikasi mendeley desktop dalam penulisan artikel mereka. Adapun manfaat yang diperoleh mahasiswa dengan pelatihan ini adalah kemampuan dalam menyusun artikel ilmiah dengan memanfaatkan mendeley desktop sebagai pembuatan citasi karya ilmiah. Seperti yang disampaikan oleh Asmaroini dan Cahyono (2018) manfaat yang diperoleh mahasiswa dalam menulis artikel ilmiah yaitu: 1) Menyampaikan dan mengembangkan ide dari mahasiswa, 2) memberikan dampak yang akademis bagi mahasiswa, 3) memiliki karya berupa artikel ilmiah yang bisa dipublikasikan pada jurnal nasional, maupun internasional.

\section{PENUTUP}

Kegiatan pelatihan penggunaan aplikasi mendeley desktop telah dilakukan pada mahasiswa semester akhir prodi PPKn Universitas Muhammadiyah Ponorogo yang diikuti oleh 66 peserta dengan tambahan 6 dosen pembimbing mahasiswa. Pelaksanaan kegiatan pengabdian ini dilakukan dalam dua kali pertemuan dengan menggunakan bantuan platform zoom dengan keterbatasan pertemuan secara langsung akibat dampak pandemic covid-19 yang dianjurkan tidak melakukan kegiatan pertemuan secara tatap muka. Pertemuan pertama pada Hari Selasa tanggal 02 Juni 2020 yang difokuskan pada penyampaian materi dasar serta pentingnya penggunaan aplikasi mendeley desktop untuk mempermudah melakukan citasi dalam pembuatan karya ilmiah atau tugas akhir. Pada pertemuan kedua yang dilaksanakan pada Hari Selasa tanggal 09 Juni 2020 difokuskan dalam pengecekan hasil pembuatan mini artikel ilmiah yang sudah menggunakan aplikasi mendeley desktop.

\section{DAFTAR PUSTAKA}

Arista, Riska, Fajar. 2015. Plagiarisme di Kalangan Mahasiswa: Paradigma. 03 (2), 1-5.

Asmaroini, Ambiro, Puji. \& Cahyono, Hadi. 2018. Pelatihan Pembuatan Artikel Ilmiah bagi Mahasiswa Prodi PPKn Universitas Muhammadiyah Ponorogo: J-ABDIPAMAS (Jurnal pengabdian kepada masyarakat). 2(2), 9-12.

Departemen Pendidikan Nasional (Depdiknas). (2008). Kamus Besar Bahasa Indonesia Pusat Bahasa Edisi Keempat. Jakarta: PT Gramedia Pustaka Utama.

Fitriana, H. A., Octaviani, A., Dewi, P., Studi, P., Perpustakaan, S.-I., Budaya, F. I., ... Referensi, D. 
2014. Pengaruh Pengajaran

Mendeley

Reference

Management

Software

Terhadap Ketepatan Penulisan

Sitasi Dan Daftar Referensi (

Studi

Eksperimental

Mahasiswa Prodi S-1 Ilmu

Perpustakaan Angkatan 2014

Universitas Diponegoro).

Ginanjar, A. 2018. Peningkatan

Mutu Karya Tulis Dosen FIS

Dengan

Menggunakan

Reference Manager Software

Mendeley: Harmony, 3(2), 199203.

Hal, A., Windarto, A. P., Hartama, D., \& Wanto, A. 2018. Pelatihan Pemanfaatan Mendeley Desktop Sebagai Program Istimewa Untuk Akademisi Dalam Membuat Citasi Karya Ilmiah: Aksiologiya: Jurnal Pengabdian Kepada Masyarakat. 2(2), 145-150.

Shadiqi, Muhammad Abnan. 2019.

Memahami dan

MencegahPerilaku Plagiarisme dalam Menulis Karya Ilmiah: Buletin Psikologi. 27 (1), 30-42. Septiyani, Tri. (2015). Plagiarisme di Kalangan Mahasiswa. Kompasiana edisi 24 Juni 2015, bisa diakses melalui https://www.kompasiana.com /tseptiy/55291775f17e61e1348b 4659/ plagiarisme-di-kalangan- mahasiswa.

Wahyuni, Nur, Cahyati. 2018. Ketika plagiarisme adalah suatu permasalahan etika: Record And Library Journal. 4(1), 7-14.

Windarto, Agus, Perdana. dkk. 2018. Pelatihan Pemanfaatan Mendeley Desktop sebagai Program Istimewa untuk Akademisi dalam Membuat Citasi Karya Ilmiah: Aksiologiya Jurnal Pengabdian kepada Masyarakat. 2(2), 145150. 